\title{
A NEW DIGITAL TEST PLATFORM OF MICRO-GRID SYSTEM BASED ON RTDS GENERAL MODEL
}

\author{
Liu Tao ${ }^{a}$, Wang Xudong ${ }^{b}$ \\ Tianjin Electric Power Corporation Electrical Power Research Institute, Tianjin, China, \\ a net_liutao@126.com, b wangxudong@126.com
}

Keywords: micro-grid, digital simulation platform, Tianjin eco-city, RTDS

\begin{abstract}
This paper presents a micro-grid digital simulation and platform based RTDS. The common distributed generators and energy storage elements are modeled and can be constructed to form the micro-grid. Considering the micro-grid control, the platform builds the PQ control in parallel operation, V/F control and Droop control in island operation. Examples of sino-singaporean Tianjin eco-city micro-network project simulation prove the correctness of the proposed digital simulation platform.
\end{abstract}

\section{Introduction}

With the development of micro-grid(MG), the simulation technology is drawing increasing attention[1],[2]. So far, the MG simulation mainly includes physical simulation and digital simulation. Due to the advantage in the economy and flexibility, digital simulation is more competitive than physical one. Based on computer hardware and software platform, many MG-related issues can be studied and analyzed, such as distributed generator operation and control [3], MG energy monitoring and management[4],[5], fault transients analysis[6], etc.

In this paper, a real-time digital simulation(RTDS) for the simulation of the MG is established and provides the interface between the physical device and RTDS. The common distributed generators and energy storage elements are modeled and can be constructed to form the micro-grid. Considering the micro-grid control, the platform builds the PQ control in parallel operation, V/F control and Droop control in island operation. Examples of sino-singaporean Tianjin eco-city micro-network project simulation prove the correctness of the proposed digital simulation platform.

\section{Main contents}

\subsection{MG unit model}

2.1.1 Wind power model

The wind turbine captures the wind power and exports mechanical torque. In RTDS, a package wind turbine is provided as figure 1.

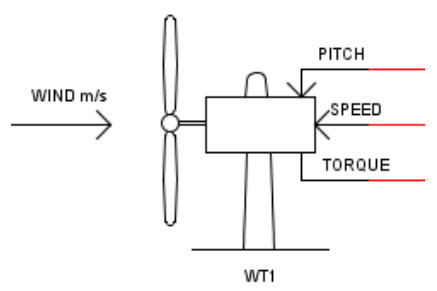

Figure 1 Wind turbine model

The wind power generation control system is mainly composed of variable pitch control, the motor side converter control and the grid side converter control. Three typical control models should be considered in order to form commonly used generation, that doubly fed induction generator(DFIG) or direct drive permanent magnet generator(DPMG). Figure 2 shows the variable pitch control of DFIG in RTDS. Figure 3 gives the back-to-back system and PWM pulse generating module of DPMG in RTDS. 


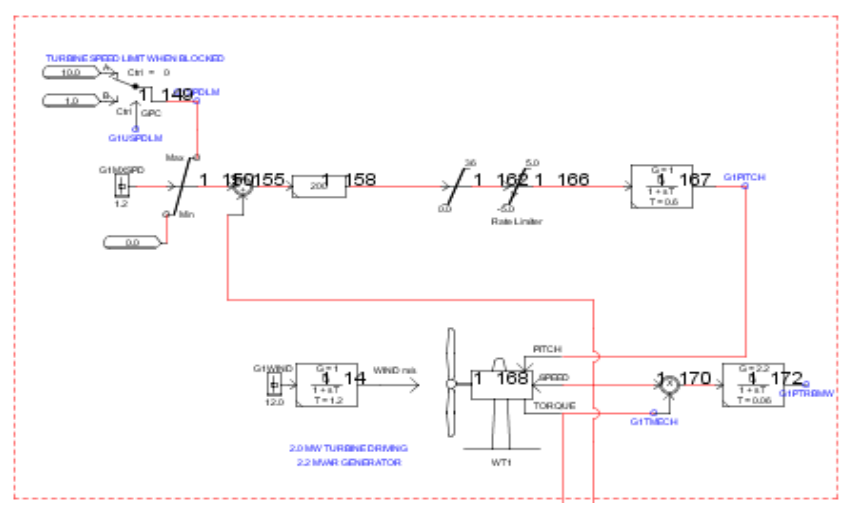

Figure 2 Variable pitch control model of DFIG in RTDS

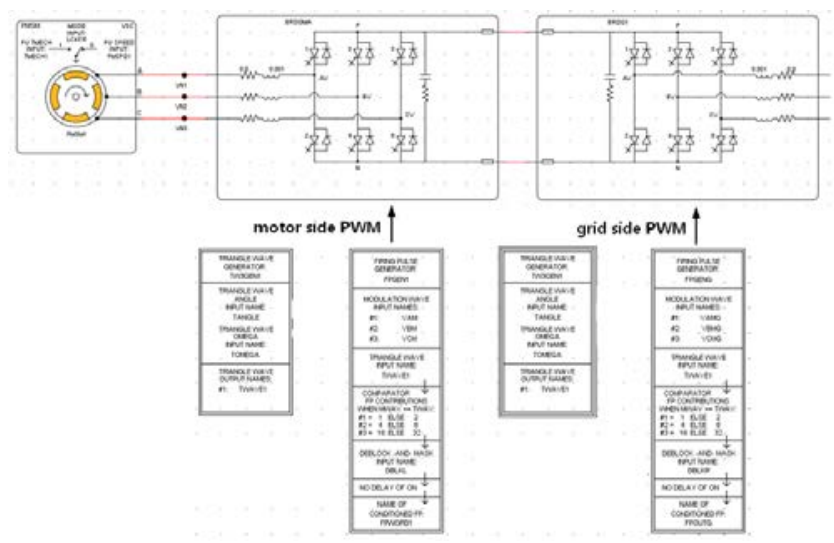

Figure 3 Back-to-back system and PWM pulse generating module of DPMG in RTDS

\subsubsection{Photovoltaic Power model}

The single-phase two-stage system is most common photovoltaic generation, as shown in figure 4, which is composed of photovoltaic array, DC/DC converter, DC/AC inverter, controller and filter. The package model of photovoltaic array is available In RTDS shown in figure 5 . The other parts is similar to the wind power control system discussed above.

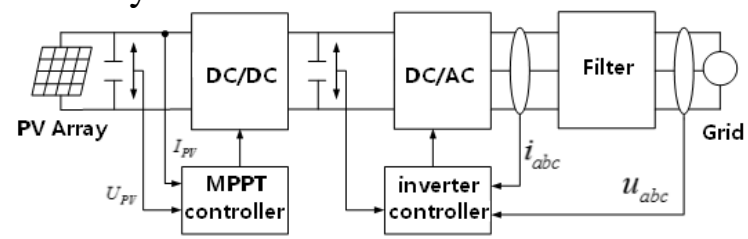

Figure 4 Single-phase two-stage photovoltaic generation system

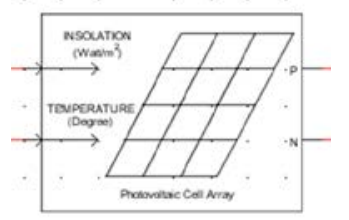

Figure 5 Photovoltaic array model

\subsubsection{Micro gas turbine model}

Micro gas turbine uses the heat generated by the combustion of combustible gas or liquid to drive the permanent magnet motor rotation and generation. Micro gas turbine control system consists of a micro gas turbine, the permanent magnet synchronous generator, rectifier, inverter and control part. The control part of micro gas turbine system includes gas turbine is controlled mainly by the control of the rectifier control and inverter. The control principle of rectifier and inverter is the same as the direct drive permanent magnet discussed above. Control of the gas turbine including speed control, acceleration control, temperature control and fuel control is shown below. 


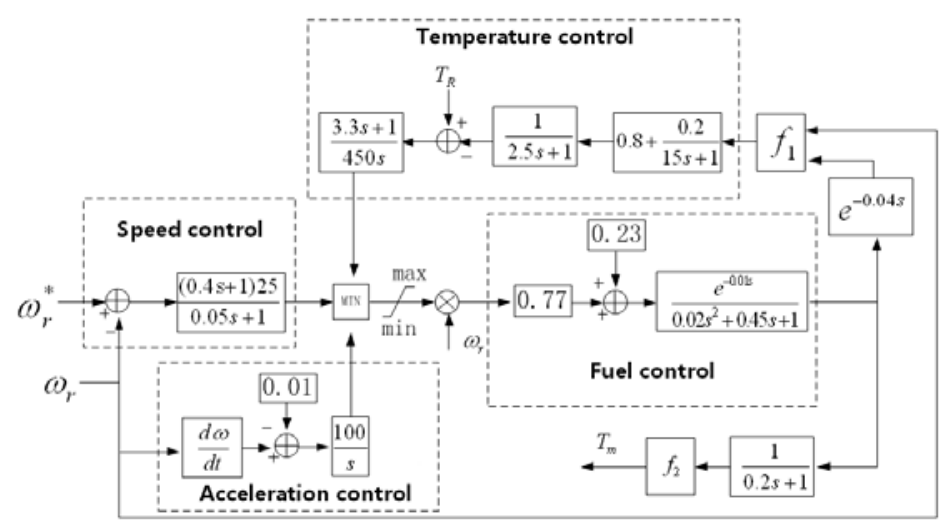

Figure 6 Block diagram of control system of gas turbine

\subsubsection{Energy storage model}

The energy storage system consists of two portions of the battery model and power conversion system model. The battery model can be established with controlled DC voltage source, whose signal can be provided by the battery model corresponding, as shown in figure 7 and 8 respectively.

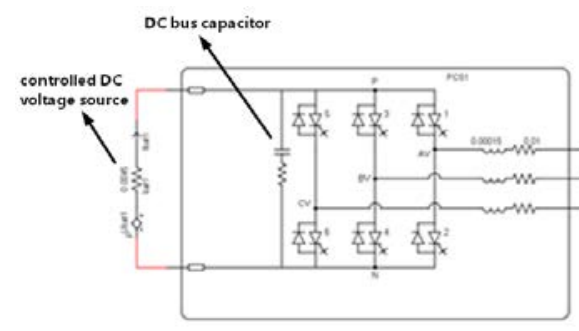

Figure 7 Energy storage system model
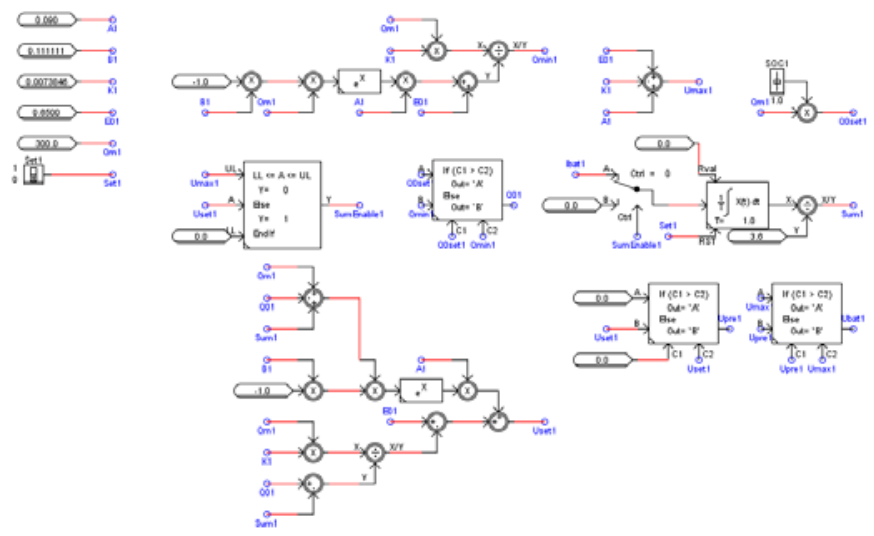

Figure 8 Detailed model of the battery

\subsection{MG system model and control strategy}

Composed of distributed generators discussed above, MG operation should be considered. There are three modes of operation: grid connected operation, islanding operation and the switching operation. In order to ensure the safe and effective operation of the MG, the control of MG is the most important when the MG structure changing and the load fluctuation.

\subsubsection{Grid-connected operation}

In the mode of grid connected operation, the active and reactive power output of internal distributed generators and energy storage elements is equal to the reference power, The adjustment of frequency and voltage is completed by the main electrical grid. Therefore we can use the PQ strategy, as shown in figure below, to control the converters of the distributed units. 


\subsubsection{Island operation}

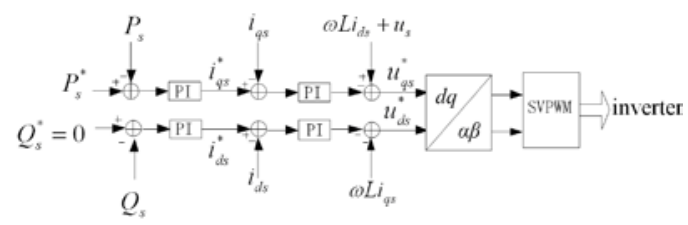

Figure 9 Structure diagram of PQ control strategy

In island operation mode, the MG must meet the load active power and reactive power demand and provide the voltage and frequency stability. In this paper, two control strategies is considered, including master slave control and peer-to-peer control.

(1) master slave control strategy

In master slave control strategy, master distributed generator maintains the MG voltage and frequency stability by taking constant voltage and frequency control (V/f control) and the other distributed generators can be used for constant power control (PQ control), as shown below.

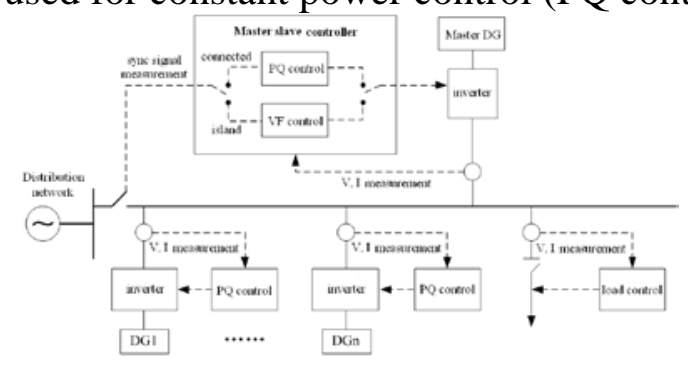

Figure 10 the MG master-slave control structure diagram

(1) peer-to-peer control strategy

In peer-to-peer control strategy, every distributed generator utilizes local electrical variables to complete operation management, with no communication to the other distributed generators. Independent from communication, using this strategy can increase the network reliability and reduce the cost of the system.

Especially, each distributed generator is undertaking the task of maintaining a MG system voltage and frequency, so each DG using V/f control. The MG peer-to-peer control structure is shown below.

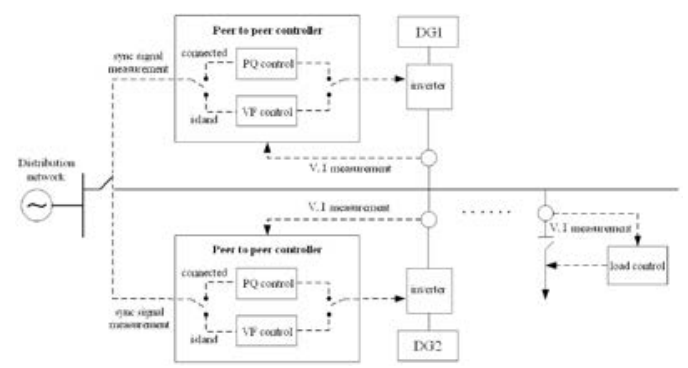

Figure 11 The MG peer-to-peer control structure diagram

\subsection{Cases}

In this paper, sino-singaporean tianjin eco-city micro-network project simulation is established based on the above RTDS model in figure 12. New eco-city projects includes micro-grid photovoltaic array consisting of monocrystalline silicon photovoltaic panels totaling $28340 \mathrm{Wp}, 6$ sets of $1 \mathrm{~kW}$ small wind turbines, 2 sets of lithium-ion battery. Micro-grid load includes $10 \mathrm{~kW}$ lighting loads and $5 \mathrm{~kW}$ AC charging for electric vehicles. 


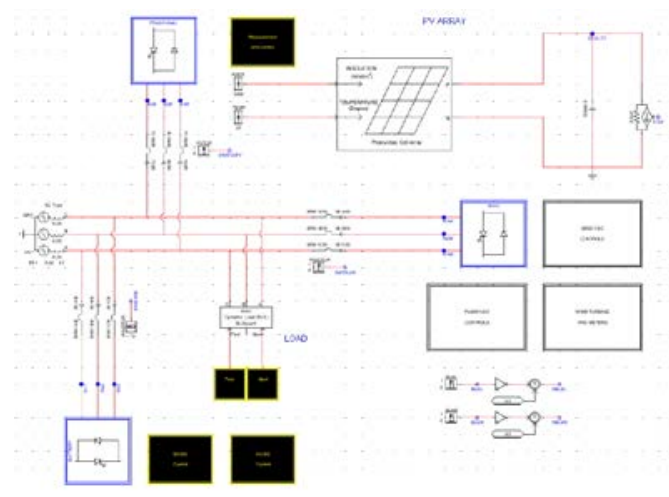

2.3.1 Steady analysis

Figure 12 The eco-city MG simulation model in RTDS

Operation data in the eco-city is shown in Figure 13 (a), (b), (c), including the energy storage in Figure 13 (a), photovoltaic power output in Figure 13 (b) shows, MG frequency in Figure 13 (c). Correspondingly energy storage, photovoltaic power and system frequency simulation waveform is shown in Figure 13 (d), (e), (f) .
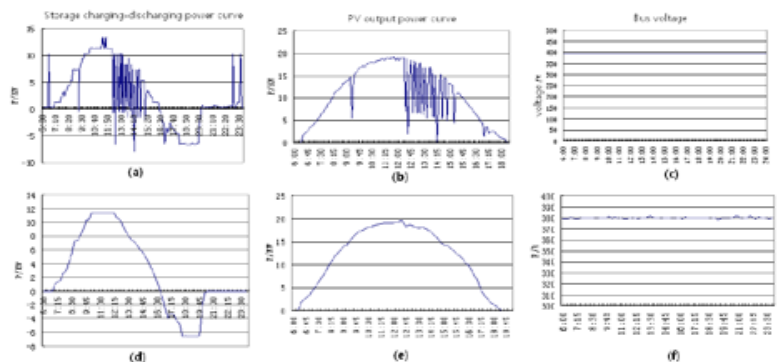

Figure 12 Comparison of the eco-city MG simulation with the actual operating data

\subsection{2 transient analysis}

This paper carried out the eco-city MG mode switching mode switchingtransient test, in which the dynamic process of wind-storage mode switching to wind-photovoltaic-storage mode is simulated. Before switching system load is $1.2 \mathrm{MW}$, wind output power is $240 \mathrm{~kW}$, the energy storage system output active power is about $1 \mathrm{MW}$. After switching, the new system should be able to continue to maintain the $600 \mathrm{~kW}$ output to reduce the fluctuation of system. From the upper to the lower figure 14 (a) shows wind output active power PM, back-to-back converter DC bus voltage Udc, wind turbine pitch angle G1PITCH and permanent magnet motor speed SPDPU. Figure 14(b) is the active power output of PV. Figure 14(c) is A phase current of wind power inverters and photovoltaic synchronizing switch signal. Figure 14 (d) is the close-up image in the switching point. From figure 14 (c), (d) it can be seen that, after PV synchronization and connection to the grid, wind turbine inverter switched to PQ control mode and each wind power output is $200 \mathrm{~kW}$. The switching process has no effect on the grid system and load. 


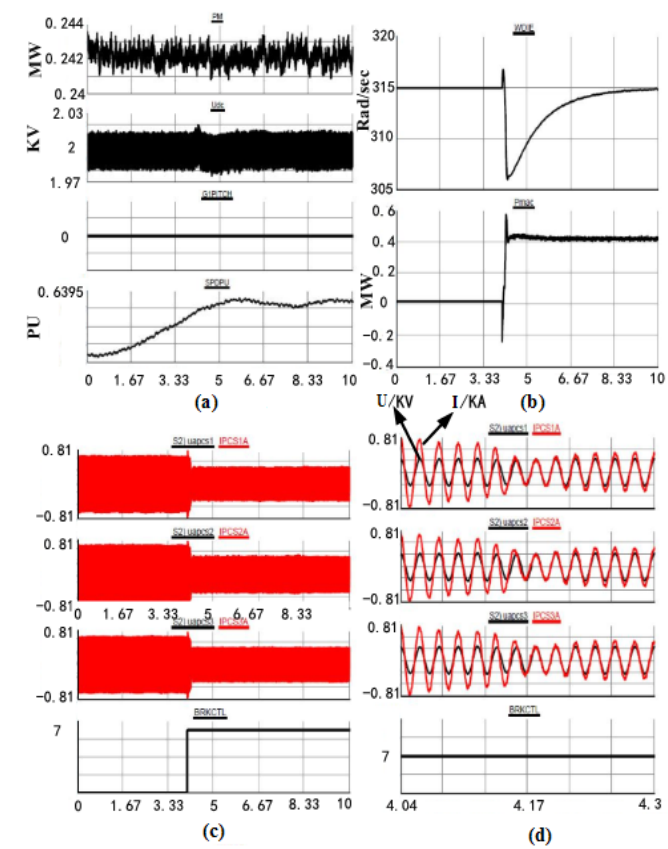

Figure 13 Simulation curve of wind-storage mode switching to wind-photovoltaic-storage mode

\section{Conclusion}

This paper built the MG unit model and system model based RTDS, and carried out simulation analysis combined with the Tianjin eco city MG system, including the steady and transient test. The experimental results show that, the micro network simulation platform built in this paper has certain guiding significance for the MG construction scheme.

\section{References}

[1] Arriaga M, Cañizares C A, Kazerani M. Renewable Energy Alternatives for Remote Communities in Northern Ontario, Canada[J]. 2013, 4(3): 661-670.

[2] Lukuyu J. Wind-diesel microgrid system for remote villages in Kenya[C], North American Power Symposium (NAPS), 2012. IEEE, 2012: 1-6.

[3] Abbey C, Joós G. A stochastic optimization approach to rating of energy storage systems in wind-diesel isolated grids[J]. Power Systems, IEEE Transactions on, 2009, 24(1): 418-426.

[4] Ross M, Hidalgo R, Abbey C, et al. Energy storage system scheduling for an isolated microgrid[J]. IET renewable power generation, 2011, 5(2): 117-123.

[5] Sebastian R, Pena-Alzola R. Simulation of a wind diesel system with a Ni-Cd battery energy storage[C], Power Engineering, Energy and Electrical Drives (POWERENG), 2011 International Conference on. IEEE, 2011: 1-6.

[6] Tankari M A, Camara M B, Dakyo B, et al. Use of Ultracapacitors and Batteries for Efficient Energy Management in Wind-Diesel Hybrid System[J].2013, 4(2):414-424. 